\title{
SPECIFIC SELECTIVE MEDIA INSPIRING IDEAS OF VISUAL EXPRESSION IN THE ARTISTIC SPACE: AN APPLIED STUDY IN THE FIELD OF PAINTING FOR THE INTERPHONE AND TRANSIENT EXHIBITION "THE MEDIUM SURVIVAL AND THE SURFACE IS A VISUAL PASSION" \\ Hadeel Muhammad Aziz Nazmi SALEM* \\ Painting Department, Faculty of Fine Arts, Alexandria University, Egypt
}

\begin{abstract}
The values of employing the mediator in the space of the painting varied, exploring the role of technology and experimentation in the dimensional and physical systems, and the relationship between form and function continued to accompany the artwork for material purposes, the mediator has played the role of the material carrier at some times, while in this research it is intended the aesthetic role and being a subject on which the idea of the artistic work itself depends that it is a re-exploration and interpretation of the medium in its ability to multiply and cross the limits of techniques and trends pertaining to artistic work to form a kind of mixing with digital technology and contemporary quality concept and to become a source of aesthetic construction among the specific interactions of the performances accompanying the artistic work space. The medium represents a material that can be added and treated for a purpose that goes beyond the construction of the visual plastic concept. Rather, it reached through the experiments of painting space and artistic work to the point of theorizing for modernist projects and trends that exceeded the limits of classification and different visual styles from the means of expression with materials and technical means, as it became crossing the limits of science and aesthetic and expressive formulas overcoming the temporal and spatial determinants of the space of the artistic work. The necessity of selective visual media with artwork and painting is not in its being to reproduce images of visible reality, but in its ability to make what is beyond the visible world a visible world. The visual medium is a diacritical language loaded with the artist's own experience in terms of expression, imaginative flexibility, a tendency towards experimentation, the ability to analyze, visual and formal composition, possessing an independent language, and the possibility of aesthetically linking the technological and technical dream world with the real world and by selecting the medium the surface turns into a visual passion. So it takes us directly to the world of art and calls for the relationships of things and their multiple phenomena to reach modernist stages of creative perception of artistic work.

Keywords

Media Inspiring Ideas, Visual Expression, The Artistic Space, Painting, The Interphone, Transient Exhibition.
\end{abstract}

\section{Introduction}

Science and art were able to reach the top of the degrees of blending to achieve the most beautiful image to blend the product of the mind and conscience in order to advance human civilized values and to achieve a better life for the human being on this earth so that plastic practices evolved by being affected by the scientific expansion and its techniques throughout the history of arts to become the tool, the mediator and the engine of the artist's ideas.

The human nature employed by human thought to facilitate life as well as to express it and in it has become the implementing tool for ideas, and the other side of the concepts of rapid development and their presentation of models that present a different thought, and assume the

* Corresponding author: finea-dean@alexu.edu.eg 
task of arousal, given the high-precision technical perceptions it offers in terms of building a new aesthetic perception that allows the recipient to explore multiple areas of vision, therefore, it pushed the artist to search through it without thinking about the technical obstacles that might hinder the material presentation of his ideas and opinions.

In addition, it undertook the task of transferring, displaying, and preserving the work so that the recipient could keep up with artistic practices regardless of the difference in place and time which can be identified through contemporary practices.

These features overlooking us from the development of human thought and its control over the technological machine have directly contributed to the development of the intellectual and cultural discourse of the modern-day human being, as the specific shifts in the media of expression have achieved development on all levels, they represented in one way or another confirmation of the progression of human time as what we have reached today is a continuation of yesterday's research, and as a result of the artists' experiences and their reference that the intellectual material needed to develop and was not without the terrible desire and power to change the mind and its apostasy to drain the signals of nature and achieve completeness, and the search for aesthetic facts to reach the truth.

The language of the mind today in which technology represented its communicative $\mathrm{ABCs}$ as an extension of the contributions of the past to become the only place and entrance to the journey in time, in geography in which the information culture dominated the minds of creators pushing them to keep up with the times and producing of an artistic culture synonymous with the scientific expansion of what the latter is witnessing in rapid development in which it overlooked the functional dimension of production to become an independent language in itself looking for creative action in the search for completeness, distinction and uniqueness.

Thus, specific technology represented an intellectual approach through which the artist deals with intellectual systems in a distinctive philosophical vision and presents his perceptions of the future in how the image is no longer an obsession with the artistic construction as much as it has become the mental language for dealing with the world and stirring its successive ideas, in search of keeping pace with the scientific tide and methods of experimentation accompanying it, raising its problems and presenting its ideas as materials for aesthetic construction and artistic practice, until what the artist reached in changing the materials that the artistic thought used to work with in order to transcend the space of the painting, the frame and the medium to become, for example, the body is the substance on which he works and the material that carries ideas from the principle of the transformation of contemporary artistic 
practices towards technology as it has sometimes become an ontological study that discusses the morphology of art and artistic practices from a creative principle accompanied by the technological transformation of thought that has become an aesthetic construction of contemporary artistic practices.

\section{Research Problem}

1. Is the multi-medium an aesthetic subject of the artistic work space?

2. Is it possible to mix among visual methods overcoming the ideas of identification and descriptive classification of the painting?

3. Can digital technology give a new identity to the recognized styles and performances and blend them to produce modern art formations?

4. Does the shape of the artistic work and the painting change with the experimental innovations of style and technology?

5. Is the mediator a contemporary means of expressing ideas for forms of modernist practices in art today?

And through a group of works from the medium and transient exhibition of the researcher, practical application has been made to these multimedia works, as they present the research problem in the use of specific multimedia as inspirations for artistic work.

\section{Research Objectives}

The research aims to re-present the idea of visual expression through the different specific media recognized which are not limited to technological methods but transcend the various uses of the material in the techniques of painting and the flat space of work.

\section{Research Methodology}

The study was based on the analytical and critical method related to aesthetics for periods of transformation from the uses recognized throughout the history of art to the media up to the scientific and technological transfers and multimedia that reshaped the creative concepts of the artistic work space.

\section{Results}

1. The research results varied based on the research in the theoretical side and the intellectual and aesthetic background of the research topic where the research presented the multiplicity of mediator concepts among specific media related to the material, media related to the style or aesthetic media related to the transition from one artistic identity to another in the space of artistic work.

2. The research proposed the concept of integrating visual media inspired by the idea of multimedia that is sometimes combined with technology to give the material medium 
a technological feature that is reused in artistic work such as converting the pictorial methods recognized on painting surfaces after being combined in technical treatments to other artistic methods through using the idea of a transient or medium to move from a pictorial surface to another pictorial surface without changing the formal values of the work.

3. There are several spaces that can change the visual dimensions of the work especially in the pictorial surface of the work, the use of the method of combining the pictorial surfaces in one work that combines drawing, painting and printing and presenting it in the form of a book contributes to creating another visual dimension in the middle of the space between the surface of the painting and its outer frame, as is the case in the first applied work, these visual dimensions which the medium contributed to creating added imperceptible aesthetic dimensions to the artistic work, including the temporal count and the expansion of the scope of vision and imagination of the viewer as well as expanding the ranges of artistic expression within contemporary modernist frameworks.

4. The visual space depended on two factors, a technical factor and an experimental factor, which made the produced works not subject to a specific optical law, but variable according to the movement among different media, whether they were physical media (painting, printing and drawing) or technical media (digital media, computer and print processors).

\section{Recommendations}

The difference in the semantic interpretation of multimedia in contemporary arts represents an important stage in the field of aesthetics of arts and techniques where the transition from traditional concepts of painting media, drawing, engraving and multimedia to experimental activity among these methods and linking them to the multiplicity of the medium in the artistic work and developing the methodology in proposing suggested methods for the contents of teaching the new applied aspects of design, painting and drawing.

\section{References}

1. Amhaz Mahmoud: Contemporary Fine Art 1870-1970 Painting, Triangle House for Design, Printing and Publishing, Lebanon, Beirut 1981.

2. Rady, Hakim: The Philosophy of Art for Susan Langer, Ministry of Culture and Information, House of General Cultural Affairs, 1986. 
3. Stolentitz, Jerome: "Art Criticism", Translated by: Fouad Zakaria, Ain Shams University Press, Cairo, 1974.

4. - Shukri Abdul-Alah Hussein: Space in Creative Work, (D.N), 2003.

5. Abboud Farag: The Science of the Elements of Art, Part 1, Dolphin Publishing House, Milan, Italy 1982.

6. Kamel Muhammad Muhammad Aweidah: Part 10 of the Psychology Series, an Introduction to the Science of Art and Beauty.

7. Malins, Frederick: "Painting, How to taste it?" translated by: Hady Al-Taie, House of General Cultural Affairs, Baghdad, 1993.

8. Nobler Nathan: The Dialogue of Vision: An Introduction to the Taste of Art and the Aesthetic Experience, translated by Fakhri Khalil, reviewed by Jabra Ibrahim Jabra, AlMamoun House for Translation and Publishing, Baghdad 1987.

9. Heigl: The Art of Painting, translated by George Tarabishi, Dar Al-Tale'ih for Printing and Publishing 1980.

10. Alain Voir: iCrescivicc, Lestervitoires celiniens paris, Ed. Klincksiek, 1999

11. Michel Raimond L'Expression de l'espace dans le Nouveau Roman, in postions et,oppositions surle roman contemporin .cit, Ed. PUF, paris, roman du lunivers, oulet Real, Borneuf Rpland, 1981

12. Winston and Renhart. today art; Faulkner, Ray New York, Inc, 1969

13. york New Publications Gubtill Watson, artists for Gide complete collage: Anne, Brigandier, london, Puplishing pitman, 1970

14. Hill, McGraw, York New (Art Anti and Art: Dada) Hans, Richter, 1965

15. London, hudson and Themes, Picasso, Robert Mallard\& Frank, Edgar, 1960

16. Moataz Enad GHAZWAN, INTELLECTUAL AND HISTORICAL REFERENCES AND THEIR REFLECTIONS ON CONTEMPORARY APPLIED ARTS CARPETS AS A MODEL, International Journal of Multidisciplinary Studies in Art and Technology, Vol. 2, No. 1, 2019, pp. 12-20.

17. Imene M. CHALLOUF, LA PHOTO- UNE PRATIQUE DU SUPPORT (POÏETIQUE D'UNE EXPERIMENTATION PLASTIQUE AUTOUR DU SUPPORT PHOTOGRAPHIQUE), International Journal of Multidisciplinary Studies in Art and Technology, Vol. 2, No. 1, 2019, pp. 21-31. 